\title{
Aluminium intoxication in undialysed adults with chronic renal failure
}

\author{
Louis S Russo, Gregory Beale, Stephen Sandroni, William E Ballinger
}

\begin{abstract}
The dialysis encephalopathy syndrome (DES) consists of altered mental status, communication difficulty, seizures and myoclonus. It has been attributed to elevated serum aluminium (A1) levels. Two undialysed patients with chronic renal failure who presented with the characteristic syndrome are reported. The first, a 48 year old female, had used A1 containing phosphate binders for two years. Her serum A1 level was $25 \cdot 34 \mu \mathrm{mol} / \mathrm{L}$. Despite treatment with desferoximine and dialysis, she died. Necropsy revealed elevated A1 levels in the cerebral cortex $(19 \mathrm{mcg} /$ gm) and spongioform change in the outer three cortical layers. The second patient, a 46 year old woman, had a serum $A 1$ of 8.70 $\mu \mathrm{mol} / \mathrm{L}$. She had never taken A1 containing phosphate binders but had taken several grams/day of citrate for at least six months. Treatment with haemodialysis and discontinuation of the citrate produced a resolution of symptoms and return of the A1 level to normal. During two years of haemodialysis there has been no recurrence.
\end{abstract}

(F Neurol Neurosurg Psychiatry 1992;55:697-700)

The dialysis encephalopathy syndrome (DES) was first described by Alfrey in 1972. ${ }^{1}$ It is a progressive disorder characterised by seizures, myoclonus, halting or frankly aphasic speech, dementia, and altered consciousness. It has been most commonly reported in patients with chronic renal failure receiving haemodialysis. An increase in brain Al secondary to high levels in the dialysate is the presumed aetiology. ${ }^{2-4}$ More recently, a few undialysed adults with chronic renal failure have been reported with aluminum intoxication related to the ingestion of $\mathrm{A} 1$ containing phosphate binders. ${ }^{5}$ We report two adults with chronic renal failure who developed DES before dialysis was initiated. The relationship between renal failure, increased absorption of dietary or environmental aluminium, and the development of DES is discussed.

\section{Case reports}

Case 1

A 48 year old, normotensive woman with elevated blood urea nitrogen $(20.0 \mathrm{mmol} / \mathrm{L})$ and creatinine $(468.2 \mu \mathrm{mol} / \mathrm{L})$ was referred for evaluation. General physical and neurological examination were normal. All other laboratory studies were normal except for a microcytic anaemia (haematocrit, 20\%; MCV, $78 \mathrm{cu}$ microns) and proteinuria ( $1 \mathrm{gm} / 24$ hours). No specific cause for the renal disease nor the anaemia was defined.

Hyperphosphataemia $(1.94 \mathrm{mmol} / \mathrm{L})$ and a metabolic acidosis $\left(\mathrm{CO}_{2}=13.6 \mathrm{mmol} / \mathrm{L}\right)$ developed. Aluminium hydroxide $(3840 \mathrm{mg}$ / day) and a citrate solution were prescribed. During the following 18 months her renal function continued to gradually decline (blood urea nitrogen $11.5-19.6 \mathrm{mmol} / \mathrm{L}$, creatinine $530 \cdot 4-654 \cdot 2 \mu \mathrm{mol} / \mathrm{L})$, but she remained asymptomatic.

Two years after initial presentation, before the initiation of dialysis, she presented with simple partial seizures involving her left-sided extremities and halting speech. Neurological examination during the interictal phase revealed an intact mental status, halting but non-aphasic speech, normal cranial nerve function, and generalised hyper-reflexia without weakness or sensory deficit. CT of the brain and CSF examination were normal. Carbamazepine was started. Within 3 days, however, her speech became less fluent with occasional, paraphasic errors. Multi-focal myoclonus developed, the left simple partial

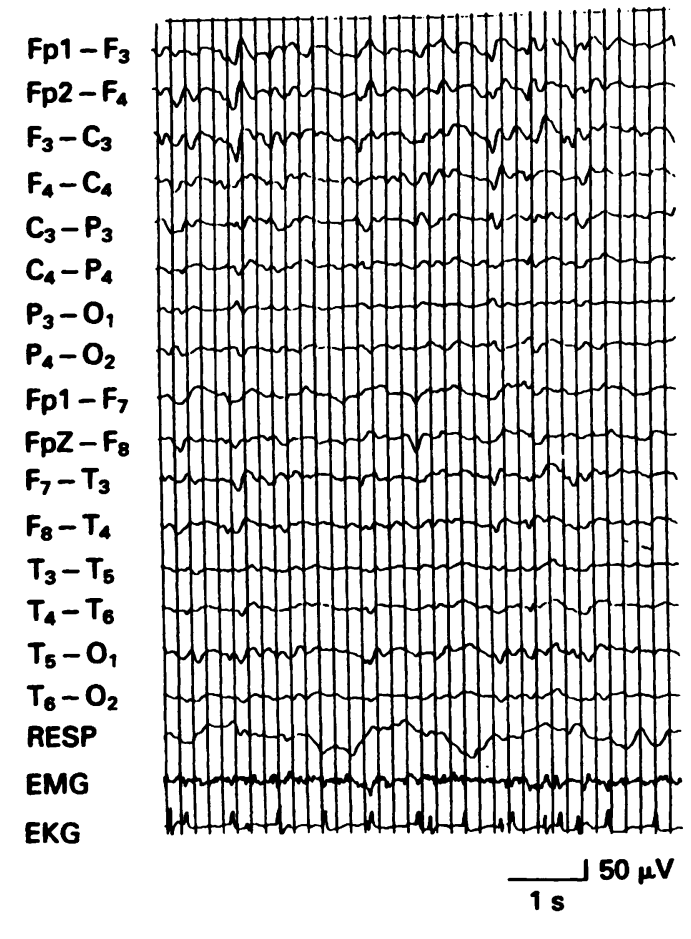

Figure 1 EEG in case 1; blood aluminium level $25 \cdot 3 \mu \mathrm{mol} / \mathrm{l}$. 
seizures continued, and her sensorium became depressed. An EEG (figure 1) showed a slowed background with mixed theta and delta activity and intermittent generalised bursts of paroxysmal sharp waves. Blood urea nitrogen at that time was $14.3 \mathrm{mmol} / \mathrm{L}$, and uraemia seemed an unlikely aetiology. Dialysis was, however, carried out twice without improvement. A serum aluminium level was $25 \cdot 3 \mu \mathrm{mol} / \mathrm{L}$. Aluminium concentration in the dialysate was $0.77 \mu \mathrm{mol} / \mathrm{L}$.

Chelation therapy with desferoxamine and dialysis was initiated. The serum aluminum level initially increased to $33.1 \mu \mathrm{mol} / \mathrm{L}$ but then gradually decreased to $0.26 \mu \mathrm{mol} / \mathrm{L}$ after two weeks of therapy. The myoclonus and seizures waxed and waned. Her speech became less

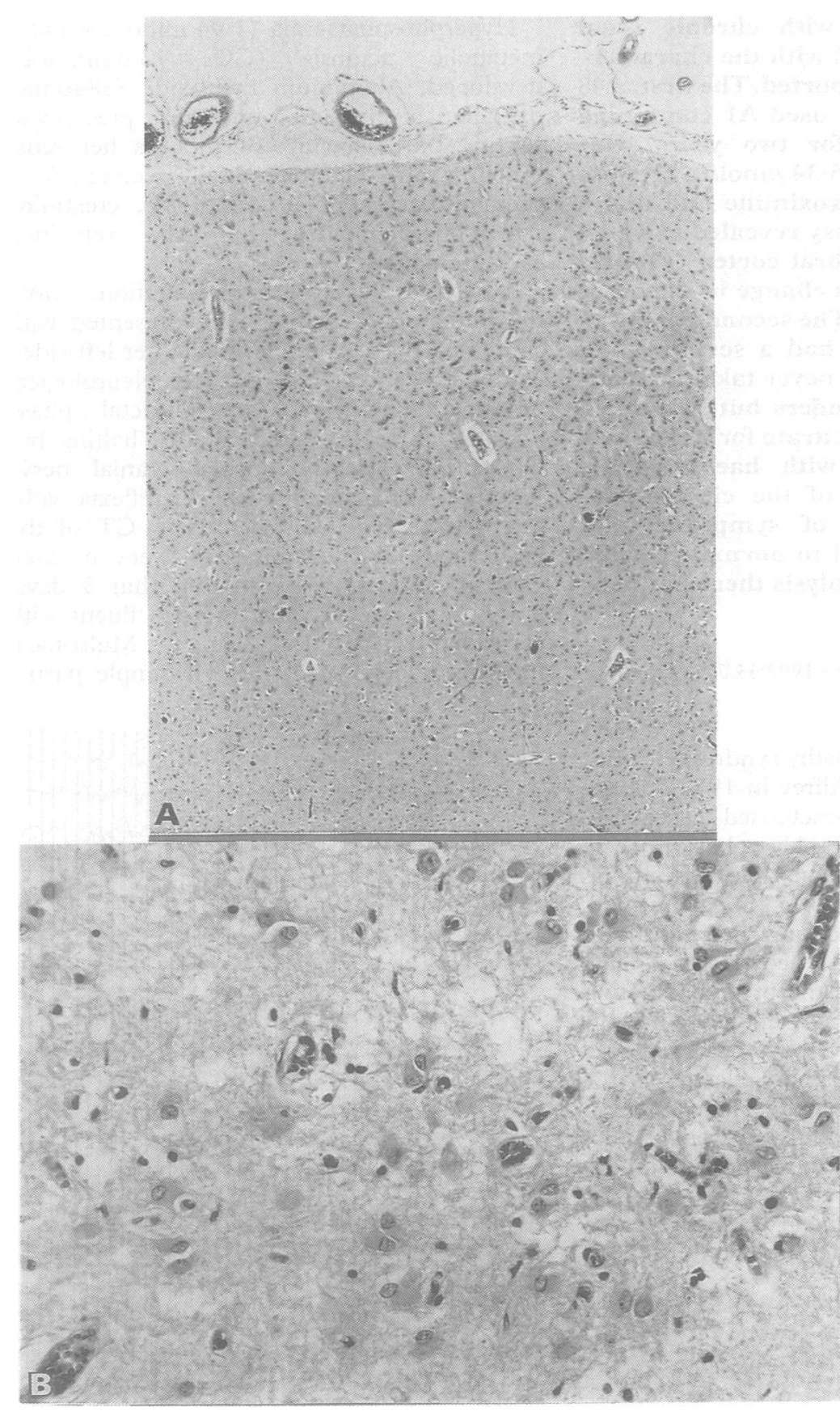

Figure 2 a) An area of frontal cortex showing spongy degeneration of the upper third with gliosis. The overlying meninges, lower level of the cortex and the subcortical white matter show no pathological changes. (Hemotoxylin and eosin $40 \times$ ); $2 b$ ) At higher magnification, the spongiform change with neuronal drop out and fibrillary astrocytosis is evident. (Hemotoxylin and eosin $250 \times$ ). coherent. Her level of consciousness fluctuated from alert to lethargic, and serial EEGs showed gradual worsening. The chelation therapy was stopped after 5 weeks, but dialysis continued. Septicaemia developed, and she died on the fifty fifth hospital day.

Necropsy examination showed nephrosclerosis with PAS positive, amyloid negative, glomerular change. Osteodystrophy was absent. Bone marrow aluminium was $45 \mathrm{mcg} / \mathrm{gm}$ (nor$\mathrm{mal}<75 \mathrm{mcg} / \mathrm{gm}$ ). Gross examination of the brain showed no significant abnormalities of the meninges. There was mild, diffuse cortical atrophy. No softening or oedema was present. There was no significant atherosclerotic disease of the major vessels at the base of the brain. Hemotoxylin and eosin stained sections from the cerebral cortex revealed areas of spongy degeneration involving the outer three layers (figure $2 a$ and $b$ ). In these areas there was neuronal loss and a reactive fibrous astrocytosis. This pathological change involved sections from the frontal and temporal cortex and blended into areas that were normal. No inflammatory changes were identified. The lower levels of the cortex showed well preserved neurons with no spongy change or glial reaction. The white matter was unremarkable. Sections of basal ganglia, thalamus, cerebellum, and hippocampus revealed no pathological changes. Modified Siever-Munger stains revealed no senile plaques, neurofibrillary tangles or Pick bodies. Aluminum concentration in the frontal lobe grey matter was elevated at $19 \mathrm{mcg} / \mathrm{gm}$ (normal $<5 \mathrm{mcg}$ ) gm).

\section{Case 2}

A 45 year old hypertensive woman was admitted in acute renal failure (blood urea nitrogen $50 \mathrm{mmol} / \mathrm{L}$, creatinine $1282 \mu \mathrm{mol} / \mathrm{L}$, and phosphate $2.55 \mathrm{mmol} / \mathrm{L}$ ) presumed secondary to chronic abuse of aspirin. She had also taken 4-6 grams of citrate in the form of Alka-Seltzer for at least six months before admission. Neurological examination was remarkable only for somnolence and disorientation. A single dialysis treatment produced a marked clinical improvement with return of normal sensorium. A more detailed neurological examination at that time was normal. However, the patient's blood urea nitrogen and creatinine remained elevated at $20.4 \mathrm{mmol} / \mathrm{L}$ and $707 \cdot 2 \mu \mathrm{mol} / \mathrm{L}$. Over the following 10 days, the patient's condition gradually worsened as her blood urea nitrogen and creatinine increased to $25 \mathrm{mmol} / \mathrm{L}$ and $866.3 \mu \mathrm{mol} / \mathrm{L}$. A second dialysis was given with return of normal neurological function.

Chronic renal failure was diagnosed, and plans for chronic haemodialysis were made. Before her next scheduled treatment, the patient experienced a complex partial seizure with secondary generalisation. Neurological examination immediately after this revealed an alert woman with normal orientation and memory, hesitant speech with good comprehension, repetition and naming, normal cranial nerve function, sensation and muscle power. Generalised hyper-reflexia with bilateral 
Babinski signs, mild gait ataxia, and myoclonus involving both upper extremities and the left lower extremity were noted. Laboratory studies at that time showed a blood urea nitrogen of $11.1 \mathrm{mmol} / \mathrm{L}$, creatinine $477.4 \mu \mathrm{mol} / \mathrm{L}, \mathrm{Ca}$ $2.42 \mathrm{mmol} / \mathrm{L}$, and $\mathrm{Mg} 0.91 \mathrm{mmol} / \mathrm{L}$. CSF studies were normal (no cells, glucose $5.22 \mathrm{mmol} / \mathrm{L}$ and protein $0.40 \mathrm{Gm} / \mathrm{L}$ ). CT of the brain was normal. EEG revealed a background of diffuse theta and delta waves with frequent paroxysmal bursts of sharp theta and frontal triphasic waves. A serum aluminium level was $8.70 \mu \mathrm{mol} / \mathrm{L}$. A repeat level in three days was $8.89 \mu \mathrm{mol} / \mathrm{L}$. Aluminum level in the dialysate was $0.70 \mu \mathrm{mol} / \mathrm{L}$. Carbamazepine was started, and dialysis continued. Her neurological symptoms cleared over 10 days. She has remained neurologically normal during two years of follow up. A recent serum aluminium level was $0.62 \mu \mathrm{mol} / \mathrm{L}$.

\section{Discussion}

The dialysis encephalopathy syndrome (DES) is recognised as a progressive, neuronal disorder occurring in the context of chronic haemodialysis. An increase in the total body burden of aluminium may be the primary pathogenic mechanism. ${ }^{246}$

Our two cases each fit the clinical criteria, including EEG changes, for the diagnosis of DES. The brain of patient 1 also showed spongiform change in the upper layers of the frontal and temporal cortex as has been described in $\mathrm{DES}^{7}$ and elevated grey matter concentration of aluminium of $19 \mathrm{mcg} / \mathrm{gm}$ (normal $<5 \mathrm{mcg} / \mathrm{gm}$ ). The focal distribution of the spongiform change and the fact that it did not involve all cortical layers was in sharp contrast to the changes in Creutzfeldt Jacob disease. This pathological difference and the clinical setting make it extremely unlikely that this patient had CRF and Creutzfeldt Jacob disease as opposed to aluminium toxicity.

The source of the aluminium in case 1 was probably the aluminum containing phosphate binder which had been ingested at a dose of approximately 4 grams per day for more than two years. Berlyne ${ }^{6}$ demonstrated a significant gastrointestinal absorption of aluminium in patients with chronic renal failure who were taking aluminium containing phosphate binders. This absorption was enhanced in an acid milieu. The hydroxide form of aluminum, which this patient was taking, is absorbed even in non-uraemic controls who ingest $2 \cdot 2$ grams of aluminium daily. ${ }^{8}$ Citrate, which was used to treat the acidosis in this patient, increases gastrointestinal absorption of aluminium in animals. ' Once absorbed, aluminium, that is not bound to plasma proteins, is distributed to multiple body organs including the brain. ${ }^{3}$ In individuals without chronic renal failure, however, it is not deposited in high concentration in any body tissue except the lungs. ${ }^{10}$ In uraemics, acidosis or its treatment, decreased kidney function, and decreased protein binding combine to increase gastrointestinal absorption and decrease urinary excretion of aluminium. This produces an elevated total body burden of aluminium and tissue deposition.

The source of the aluminum in case 2 is less clear. She was on no aluminum containing medication and had not been dialysed. Aluminium can be absorbed through the lungs ${ }^{11}$ or through the respiratory endothelium directly into the olfactory lobes using axoplasmic flow along the olfactory nerves. ${ }^{12}$ No air-borne environmental source of the aluminium was identified in our patient, however. Increased gastrointestinal absorption of dietary aluminum must remain the likely cause.

The presence of aluminum intoxication in an undialysed patient with chronic renal failure who also has no known, unusual dietary source of aluminium has not been previously described. Had we not recently been involved in the care of our first patient, we would not have explored the possibility of aluminium intoxication. Even with this heightened awareness, our initial thought was that the elevated blood aluminum level was a laboratory error. A repeat of the level confirmed the elevation.

Arguably this patient was merely demonstrating primary neurological manifestations of her chronic renal failure. This seems highly improbable since the neurological symptoms appeared only after her renal function studies had significantly improved. It is also possible that the neurological manifestations simply reflected a prolonged postictal state. The myoclonus, unsteady gait, and halting speech, however, persisted for several days even though the seizure itself had been brief.

The conclusion that this patient had somehow accumulated aluminium with consequent neurological dysfunction seems therefore reasonable. The fairly rapid response to dialysis and removal of the source of oral citrate, both from the standpoint of clinical improvement and normalisation in blood aluminium level, may indicate that the aluminium was not tissue bound at the time of presentation. Previous studies ${ }^{13}$ have shown that patients with chronic renal failure, who were neither taking Al containing medications nor being dialysed, could develop serum A1 concentrations 2 to 4 times that of normal controls. These levels were below those associated with DES, and the patients were neurologically asymptomatic. A more recent report has indicated that oral citrate alone, when added to a patient's medication regimine, can produce a 10 -fold increase in serum Al concentration. ${ }^{14}$ These two factors working together could well explain the elevated A1 levels in our patient with no extra-ordinary source of dietary A1. Finally, one previous case of DES which was completely reversed within three to four weeks only by changing oral Al intake has been described. ${ }^{15}$ This lends credence to our contention that symptoms in our second case were related to Al intoxication rather than to her chronic renal failure.

Bakir $^{5}$ first reported aluminium intoxication in adults with undialysed CRF. He ascribed the process to citrate-enhanced absorption of orally ingested aluminum. This mechanism may have played an aetiologic role in our two 
cases. Our case 2 is especially problematical. This patient raises the concern that some adult patients with chronic renal failure may be susceptible to accumulation of enough aluminium from environmental or normal dietary sources to become neurologically impaired. This possibility has not previously been reported. These two additional adult cases are presented to make neurologists aware that patients with chronic renal failure who present with seizures, myoclonus, and delirium may have aluminium intoxication even in the absence of chronic haemodialysis.

1 Alfrey AC, Mishell JM, Burks J, et al. Syndrome of dyspraxia and multifocal seizures associated with chronic hemodialysis. Trans Am Soc Artif Intern Organs 1972;18:257-61.

2 Alfrey AC, LeGendre GR, Kaehny WD. The dialysis encephalopathy syndrome. Possible aluminum intoxicaencephalopathy syndrome. Possible

3 Flendrig JA, Xruis H, Das HA. Aluminum intoxication: the cause of dialysis dementia? Proc Eur Dial Transplant Assoc 1976;13:355-61.

4 McDermott JR, Smith Al, Ward MK, Parkinson IS, Kerr DNS. Brain aluminum concentration in dialysis encepha- lopathy. Lancet 1978;1:901-4

5 Bakir AA, Hryhorczuk DO, Berman E, Dunea G. Acute fatal hyperaluminemic encephalopathy in undialyzed and recently dialyzed uremic patients. Trans Am Soc Artif Intern Organs 1986;22:171-6.

6 Berlyne GM, Ben-Ari J, Pest D, Weinberger J. Hyperaluminumemia from aluminum resins in renal failure. Lancet 1970;2:494-6.

7 Winkelman MD, Ricanati ES. Dialysis encephalopathy: neuropathologic aspects. Hum Path 1986;17:823-33.

8 Kaehny WD, Hegg AP, Aflrey AC . Gastrointestinal absorption of aluminum from aluminum-containing antacids. $N$ tion of aluminum from alumin

9 Slanina P, Palkeborn Y, French W, Cedergren A. Aluminum concentration in the brain and bone of rats fed citric acid, concentration in the brain and bone of rats fed citric acid,
aluminum citrate, or aluminum hydroxide. Food Chem Toxic 1984;27:391-7.

0 Boegman RJ, Bates LA. Neurotoxicity of aluminum. Can $\mathcal{f}$ Physiol Pharmacol 1984;62:1010-13.

11 Alfrey AC, Hegg CA, Craswell P. Metabolism and toxicity of aluminum in renal failure. Am f Clin Nutr 1980; 33:1509-16

12 Crapper DR, Krishnan SS, Quittkat S. Aluminum, neurofibrillary degeneration and Alzheimer's disease. Brain 1976;99:67-80

13 Marsden SNE, Parkinson IS, Ward MK, Ellis HA, Kerr DNS. Evidence for aluminum accumulation in renal failure. Proc Eur Dial Transplant Assoc 1979;16:588 $\cdots 94$.

14 Sherrard DJ. Aluminum-Much ado about something. $N$ Engl F Med 1991;324:558-9.

15 Masselot JP, Adhemar JP, Jaudon MC, Kleinknecht D, Galli A. Reversible dialysis encephalopathy: Role for aluminum-containing gels. Lancet 1978;1:1386-7. 